\title{
Aprendizagens no contexto de uma atividade: um confronto teórico analisado a partir de um exemplo prático
}

\author{
EDUARDO SARQUIS SOARES \\ Universidade Federal de São João del-Rei, Ouro Branco, MG, Brasil \\ GRACE MARISA MIRANDA DE PAULA \\ Universidade Presidente Antônio Carlos, Conselheiro Lafaiete, MG, Brasil \\ MARIA LÚCIA VIEIRA \\ Prefeitura Municipal de Ouro Branco, Ouro Branco, MG, Brasil
}

RESUMO

Este trabalho propõe a convivência, na prática docente, de duas concepções conflitantes sobre aprendizagem. No debate teórico, suas matrizes se apresentam em dois paradigmas. Em um deles, compartilha-se a crença na possibilidade de se prever, em algum nível, os processos mentais que os indivíduos experimentam durante a aprendizagem. Nesse paradigma, há linhas articuladas em torno da concepção piagetiana de mudança conceitual e há pesquisadores, influenciados por Vygotsky, que propõem o que se chama de perfil conceitual. Um segundo paradigma opõe-se à possibilidade de antecipação do que se vai aprender em qualquer evento. Argumenta-se que a atividade humana é situada histórica e socialmente, sendo a aprendizagem de cada indivíduo singular e inapreensível. Avaliando o debate com base nos dados de nossa pesquisa, defendemos que mesmo perspectivas conflitantes podem ser incorporadas à atividade docente.

PALAVRAS-CHAVE

mudança conceitual; abordagem histórico-cultural; prática docente. 


\title{
LEARNING IN THE CONTEXT OF AN ACTIVITY: A THEORETICAL DEBATE CONFRONTED BY A PRACTICAL EXAMPLE
}

\begin{abstract}
This paper proposes the coexistence, in teaching practice, of two conflicting conceptions of learning. In the theoretical debate, their foundations are presented in two paradigms. In the first, the scholars believe in the possibility of predicting, at some level, the mental processes that individuals experience during learning. In this paradigm there are lines articulated around Piaget's conception of conceptual change and there are researchers, influenced by Vygotsky, who propose what is called conceptual profile. A second paradigm is opposed to the possibility of anticipation of what will be learnt in any event. One argues that human activity is situated historically and socially, and any individual's actual learning is inaccessible. Confronting the debate with data from our research, we argue that even conflicting perspectives can be incorporated into teaching activities.
\end{abstract}

KEYWORDS

conceptual change; cultural-historical approach; teaching practice.

\section{APRENDIZAJES EN EL CONTEXTO DE UNA ACTIVIDAD: UN DEBATE TEÓRICO ANALIZADO TOMANDO POR BASE UN EJEMPLO PRÁCTICO}

\section{RESUMEN}

En este trabajo se propone la convivencia de dos concepciones contrapuestas de aprendizaje en la práctica docente. En el debate teórico, sus matrices se presentan en dos paradigmas. En uno, se comparte la creencia en la posibilidad de predecir, en algún nivel, los procesos mentales que experimentan los individuos durante el aprendizaje. En tal paradigma se encuentran líneas articuladas alrededor de la concepción piagetiana de cambio conceptual, además de investigadores, influidos por Vygotsky, que proponen lo que se llama el perfil conceptual. Un segundo paradigma se opone a la posibilidad de anticipación de lo que se va a aprender en cualquier evento. Se argumenta que la actividad humana se sitúa histórica y socialmente, siendo el aprendizaje de cada individuo singular e inaprensible. Al evaluar el debate tomando por base datos de nuestra investigación, sostenemos que incluso perspectivas conflictivas pueden incorporarse a la actividad docente.

PALABRAS CLAVE

cambio conceptual; abordaje histórico-cultural; práctica docente. 
A comunicação em assuntos científicos exige o compartilhamento de conceitos com sentidos razoavelmente bem definidos. O domínio de tais conceitos, competência para o uso de uma linguagem paradigmática, representa um desafio para estudantes bem como para professores. Relações entre ensino e aprendizagem de tais conceitos sugerem questões instigantes e atraem pesquisadores voltados ao campo da educação em ciências e matemática.

A ideia de mudança conceitual fascina um número considerável de pesquisadores. Ela expressa o processo pelo qual sujeitos, que inicialmente desconhecem ou apresentam domínio vago de um determinado conceito, adquirem uma noção científica dessa concepção depois de passarem por situações de aprendizagem. Pesquisadores que adotam essa premissa dividem-se em linhas teóricas diferenciadas. De maneira geral, investiga-se a ocorrência da mudança conceitual nos sujeitos ou nas circunstâncias que colaboram ou, eventualmente, dificultam sua ocorrência. Artigos que se referem explicitamente à mudança conceitual podem ser encontrados em abundância em livros e periódicos especializados. Em educação matemática, vale mencionar os autores Merenluoto e Lehtinen (2002), que tratam da aquisição de números reais; Vamvakoussi e Vosniadou (2004), que exploram a aprendizagem dos números racionais; e Vamvakoussi et al. (2011), que discutem a diferença entre discreto e denso no universo numérico. Nessas três referências, a mudança conceitual é tratada como processo de aquisição de novos conhecimentos e o foco recai sobre o desenvolvimento cognitivo individual.

Em uma das alternativas teóricas, a mudança conceitual é entendida como uma ampliação das possibilidades de utilização de um determinado conceito, cujos possíveis significados dependem das condições do ambiente cultural no qual ele é empregado. Daí advém a ideia de perfil conceitual, ou o conjunto de significados atribuídos a um conceito conforme o ambiente em que ele aparece. Nicolli e Mortimer (2012) descrevem um estudo abordando a compreensão de morte no contexto do ensino de ciências por essa perspectiva. A mudança conceitual é aqui entendida como resultado de um processo social no qual os diversos atores compartilham saberes e negociam o desenvolvimento do conceito na direção atribuída a ele por uma determinada ciência.

Entre os enunciados teóricos que acreditam na mudança conceitual, encontram-se variações quanto à definição do próprio termo e quanto à direção do olhar do observador: se deve ser focado nos sujeitos e seus sinais de evolução ou no meio social circundante e suas influências sobre a aprendizagem dos indivíduos.

No entanto, o desafio da aprendizagem situa-se entre as ciências estruturadas e o ser humano pleno de possibilidades abertas. Não se duvida, por exemplo, do princípio de Arquimedes, cuja aceitação atravessa séculos, mas que tem seu significado revestido de detalhes singulares em cada tempo e lugar em que é ensinado ou adotado em uma atividade profissional. A diversidade de aprendizagens pode ser levada ao extremo de se considerar que não existe conhecimento que não seja situado no tempo e no espaço. Disso decorre uma impossibilidade de se prever, ou até mesmo de perceber plenamente, o que realmente se aprende em um cenário dado. Cada ator tem uma experiência de vida singular, que por sua vez estará presente no significado que essa pessoa atribui a um conceito compartilhado em determinado cenário. 
Postular a mudança conceitual implica acreditar que é possível, pelo menos em parte, prever como um conceito será assimilado ou transferido para os indivíduos. Está aí subjacente a crença de que existe um conhecimento estruturado, e estruturante, compartilhado por um meio social qualquer e tomado como referência para os processos de ensino.

Em uma perspectiva conflitante com a mudança conceitual, enfatiza-se a abertura para a novidade e a imprevisibilidade, ao menos em certo grau, dos resultados de qualquer processo de aprendizagem. Conhecimentos que emergissem em determinada atividade ganhariam diferentes significados cultural e historicamente situados, portanto, irreplicáveis. A definição de um conceito não faria sentido fora do contexto de uma atividade. Como cada atividade humana tem elementos distintivos e únicos, também a expressão de qualquer conhecimento não se reproduziria em outra condição, daí decorrendo seu caráter situacional e singular (Roth, 2012).

Há um debate teórico, comentado mais adiante, entre duas posições denominadas, de uma maneira ampla, paradigma da mudança conceitual e paradigma bistórico-cultural. Nesse debate, exemplarmente ilustrado em dois artigos publicados no mesmo número da revista Cultural Studies of Science Education, Treagust e Duit (2008) e Roth (2008) sugerem uma condição de excludência entre os dois paradigmas. Uma opção teórica que tentasse conciliar as duas posições estaria necessariamente comprometida por uma incoerência insustentável. Contudo, analisando alguns dados da pesquisa apresentada neste artigo, reconhecemos que ambas as perspectivas podem contribuir com a atividade docente, o que, a nosso ver, sugere a necessidade de se processar um refinamento do debate teórico.

Investigamos a prática docente tentando melhor compreendê-la a fim de criar alternativas de ensino conforme as condições enfrentadas nas escolas. Fornecemos recursos para que professores, trabalhando cooperativamente, reflitam sobre suas próprias práticas e encontrem caminhos de aperfeiçoamento. Entre os dados da pesquisa, uma aula escolhida para análise foi considerada especialmente apropriada para a discussão supracitada. A análise dessa aula sugere questões que podem ser endereçadas aos paradigmas conflitantes. Contribuições para a prática docente podem advir dessas abordagens teóricas diferenciadas conforme a perspectiva adotada para a interpretação dos eventos observados.

Para argumentar em favor de uma convivência entre posições teoricamente antagônicas, selecionamos essa aula de um conjunto de vídeos obtidos de experimentos em uma escola municipal de Cristais, lugarejo situado na zona rural do município de Ouro Branco, Minas Gerais.

A pesquisa será apresentada em linhas gerais. Em seguida, será retomada a discussão teórica em mais detalhes e haverá movimentos entre a discussão teórica e a descrição do episódio, com o intuito de alicerçar a posição defendida diante do debate.

\section{AMBIENTE DA PESQUISA}

A pesquisa inscreve-se em um conjunto de ações de docentes do campus Alto Paraopeba (CAP) da Universidade Federal de São João del-Rei (UFSJ), visando 
colaborar para um aperfeiçoamento do ensino nas cidades vizinhas. Privilegia a formação de professores em serviço, com foco no ensino de ciências e matemática no ensino fundamental. Partimos da convicção de que a maneira mais efetiva de se atuar na formação de professores em serviço consiste em pensar, com eles, possíveis modificações no seu trabalho. A partir daí, assumir coletivamente essas modificações em aulas compartilhadas por um conjunto de professores, gravar essas aulas em vídeo e proceder a análises dos resultados obtidos. Essa prática metodológica tem como base a análise interativa (Goulart, 2005, p.51-52) e vem sendo denominada coteaching e cogenerative dialoguing na literatura acadêmica, a exemplo de Roth (2002), Roth e Tobin (2002; 2004), Soares (2009) e Soares e Goulart (2008).

A escolha metodológica anuncia, de início, a determinação de colocar em dúvida princípios de validade universal aplicáveis à prática docente. Estão implícitos o reconhecimento da singularidade de qualquer ambiente escolar e a necessidade de haver uma imersão nesse ambiente para posteriores análises e proposta de reflexões sobre aspectos possivelmente generalizantes. A reflexão sobre o que se encontra em uma condição situada pode ter aplicabilidade mais ampla; generalizações não estão colocadas de antemão, mas poderão ser propostas com base em análises de situações reais e complexas.

Envolveram-se com a pesquisa cinco docentes lotadas em três escolas, duas na zona rural e uma na área central do município. Por opção dessas professoras, o ensino de matemática foi definido como o primeiro campo de investigação, que contou com o auxílio de seis graduandos de iniciação científica do CAP.

Entre fevereiro e abril de 2011, o grupo de professoras reuniu-se uma vez por semana para discutir suas propostas didáticas e levantar temas a serem problematizados e articulados em planos para as aulas compartilhadas. $O$ grupo de graduandos reuniu-se no CAP durante o mesmo período para tomar conhecimento dos procedimentos da pesquisa e dos planejamentos. As aulas compartilhadas iniciaram-se em maio de 2011 e estenderam-se até outubro do mesmo ano.

Os planos de aula tomaram como referência os currículos efetivamente praticados nas escolas. Evitamos romper com essa condição estabelecida, uma vez que essa não era a intenção das professoras. Os currículos estavam definidos pelas diretrizes curriculares da secretaria municipal de educação, as quais reforçam práticas tradicionais cujas críticas são bastante conhecidas. Vale destacar que oposições mais recentes ao ensino tradicional podem ser vistas em Oliveira (2009), Boylan (2010) e Weinstein e Broda (2009).

Diante das condições apresentadas, a alternativa que se mostrou mais plausível consistiu em programar atividades nas quais objetos matemáticos fossem manipulados e conteúdos curriculares, na medida do possível, transformados em desafios a serem oferecidos aos alunos.

$\mathrm{Na}$ escola de Cristais, que dista aproximadamente catorze quilômetros da sede do município, as atividades ocorreram na sala da professora Jussara, ${ }^{1}$ com alunos com idade em torno de 10 anos. Uma vez por semana, em aulas de uma hora de

1 Os nomes aqui apresentados, tanto de professores como de alunos, são fictícios. 
duração, duas professoras e o coordenador da pesquisa levaram adiante um plano de ensino, cumprindo a demanda de Jussara sobre tópicos da geometria.

Um primeiro desafio apresentado aos alunos consistiu em desenhar planificações e reproduzir modelos de pirâmides e prismas previamente construídos com papel. Seguiu-se um trabalho de desenho de polígonos regulares com auxílio do transferidor. A partir daí, os alunos fizeram uma caixa de papelão em forma prismática, que serviu como presente para os pais em sua data comemorativa. Posteriormente, os alunos foram desafiados a descobrir as onze possíveis planificações do cubo. Nas aulas seguintes, a título de fechamento do programa, os alunos desenharam os polígonos regulares, do triângulo ao decágono, e fizeram planificações e montagens dos cinco sólidos platônicos. Em parte, essa sequência de desafios endereçados aos estudantes baseou-se em uma experiência anterior, realizada em 2005, com uma turma de faixa etária semelhante a dos alunos da professora Jussara. Descrição e reflexões sobre essa experiência encontram-se registradas em Soares (2009, caps. 3 e 4$)$.

A partir de outubro de 2011, o grupo de pesquisa iniciou o processo de revisão dos vídeos e escolha de episódios considerados especialmente significativos, candidatos a uma análise coletiva. A orientação da análise se fez no sentido de que cada participante oferecesse para debate no grupo suas impressões acerca do episódio, seguindo, assim, a concepção teórica da pesquisa, sobre a qual seguem algumas considerações.

\section{TENDÊNCIAS EM CONFLITO}

A escolha da orientação teórica da pesquisa pode ser mais bem compreendida quando relacionada ao debate entre dois teóricos que advogam a mudança conceitual e um autor oponente, que se filia à abordagem histórico-cultural da teoria da atividade.

Treagust e Duit (2008) iniciam tal debate apresentando um panorama histórico das ideias básicas vinculadas às pesquisas sobre mudança conceitual que, segundo eles, remontam à década de 1970. Pesquisadores dessa corrente estão cientes de que os estudantes iniciam a vida escolar plenos de crenças previamente incorporadas que, muitas vezes, conflitam com os conceitos científicos oficiais. Então a tarefa de pesquisadores consistiria em expor a dinâmica que conduziria esses estudantes à aquisição desses conceitos.

Os dois autores seguem a tradição de diferenciar conceitos de concepções afirmando que, enquanto os primeiros são referendados pelas ciências, concepções seriam modelos mentais que os estudantes desenvolvem quando pensam sobre ideias expressas nos conceitos. Uma característica comum dos alunos seria a persistência: "[...] essas concepções e ideias são firmemente retidas e normalmente resistem a mudar" (idem, p. 298).

Dois princípios teriam inspirado os primeiros trabalhos sobre mudança conceitual: a aceitação de que um dos fatores que mais influenciam a aprendizagem consiste naquilo que os estudantes já sabem e a concepção piagetiana acerca do processo de assimilação e acomodação, além de seu método clínico de entrevistar 
sujeitos, verificando explicações que fornecem sobre fenômenos que lhes são apresentados. Posteriormente, influências dos trabalhos de Vygotsky foram assumidas por outras linhas de pesquisadores mais interessados em desvelar como discursos no ambiente escolar influenciam os estudantes fazendo evoluir suas concepções na direção do discurso científico.

Treagust e Duit agrupam essas linhas de pesquisa no mesmo paradigma da mudança conceitual, guardadas as diferenças de enfoque. Linhas que seguem a tradição piagetiana ocupam-se em verificar como os sujeitos evoluem mentalmente enquanto se relacionam com conceitos já existentes no ambiente cultural que frequentam - processos mentais que envolvem desequilíbrios, ou desestabilização de determinadas crenças e reequilibrações majorantes, ou assimilação de novas ideias em outro nível de desenvolvimento.

Rudge e Howe (2009), por exemplo, apostam na possibilidade de conduzir o ensino de maneira que possa proporcionar nos estudantes mudanças conceituais por caminhos semelhantes àqueles historicamente engendrados. A utilização de estratégias de ensino baseadas na história das ciências permanece em debate (Fernández; Gatica; Blancafot, 2010; Galili, 2011).

Pesquisadores inspirados em Vygotsky consideram que o meio cultural é constitutivo do ser humano, o que os conduz a verificar, entre outras coisas, como em um ambiente escolar os atores se influenciam mutuamente a fim de que os alunos tomem posse de determinados conceitos, os quais os habilitam a participar ativamente da linguagem compartilhada nesse espaço (Boylan, 2010; Mortimer; Scott, 2002; Scott; Mortimer; Aguiar, 2006).

Nessa vertente da mudança conceitual, observa-se uma crítica à ideia atribuída a Piaget de que há um caminho sem retorno à medida que o sujeito incorpora um novo conceito. Em oposição, assume-se o entendimento de que novos conceitos não substituem necessariamente antigas concepções, mas têm validade conforme o ambiente cultural em que são utilizados. De volta ao seu meio de origem, o aluno utiliza a concepção ali aprendida, em vez de assumir o discurso científico. Considera-se, por exemplo, a definição de peso, a qual se confunde com a ideia de massa na linguagem cotidiana. Normalmente, mesmo um cientista diz "vou pesar" quando se dirige a uma balança em uma farmácia, em vez de dizer "vou medir minha massa".

Roth (2008) opõe-se tenazmente ao paradigma da mudança conceitual. E inicia o ataque analisando um exemplo oferecido por Treagust e Duit (2008), a saber: durante uma entrevista, um pesquisador conversa com uma adolescente, Dana, citando uma analogia mencionada por sua professora em determinada aula sobre refração da luz. Essa intervenção fora um recurso para auxiliar os alunos a compreenderem a mudança de velocidade da luz como explicação para o fenômeno da refração. No início da entrevista, Dana não consegue articular a refração com a mudança na velocidade da luz; no entanto, o entrevistador faz referência à analogia que fora anteriormente apresentada em sua aula. Com isso, colaborou para que Dana compreendesse o sentido da analogia. Os autores apresentam a entrevista como exemplo de mudança conceitual em andamento.

Roth contesta a ocorrência da mudança conceitual argumentando que uma entrevista é sempre produzida coletivamente e, portanto, não permite que sejam 
feitas inferências acerca do pensamento de apenas um dos envolvidos. Faz referência à análise de discurso proposta pela teoria dos atos de fala, de John Austin, para reforçar a ideia de que a transcrição da entrevista permite apenas que se verifique o que foi oferecido pelos atores um para o outro dentro daquele contexto específico. Como espontaneamente Dana diz que não sabe, apenas concordando com o entrevistador quando a analogia é mencionada, Roth coloca em dúvida qualquer afirmativa a respeito do que ela teria efetivamente mudado durante a entrevista.

Portanto, não seria possível perceber uma mudança conceitual ocorrendo na mente de Dana em um diálogo articulado dentro do que convencionalmente se entende por entrevista, o que já teria influência sobre o comportamento de cada envolvido. Roth acusa seus adversários de não diferenciarem o contexto da entrevista do contexto da sala de aula; seria impossível interpretar com os mesmos parâmetros o que é dito em um contexto e no outro.

Há ainda uma crítica ao fato de Treagust e Duit admitirem que, no paradigma da mudança conceitual, não tem sido dada atenção suficiente ao papel das emoções no desenvolvimento dos sujeitos. Roth aponta para o caráter coletivo historicamente situado das emoções, querendo com isso, mais uma vez, acentuar a diferença entre os paradigmas, centrando essa diferença na oposição entre a visão individualista associada à mudança conceitual e a visão indissociavelmente social da abordagem histórico-cultural.

Roth afirma que os dois paradigmas geram abordagens e interpretações tão diferentes que não é possível um diálogo entre ambos. Cada um deveria seguir seu rumo até que, eventualmente, um deles se mostrasse superior a ponto de provocar o desaparecimento do outro. Insiste, no entanto, que a mudança conceitual é composta de estruturas que existem apenas na mente dos pesquisadores, se é que têm alguma existência.

Em seu ataque, Roth mira principalmente dois pontos: a consideração de mentes individuais como unidade de análise e a possibilidade de se evidenciar a ocorrência de uma mudança conceitual no ato de seu acontecimento. Além disso, Roth menciona a polissemia intrínseca aos conceitos para argumentar que o significado de um termo depende, sempre, do contexto no qual é utilizado. Portanto, é difícil prever a evolução de uma concepção para um conceito, já que o significado preciso de tal conceito não pode ser definido de antemão. Em seu favor, menciona Law (2004), o qual afirma, interpretando sua própria pesquisa, que um mesmo conceito (no caso, arteriosclerose na perna de um paciente) pode ser tratado como dois objetos diferentes, conforme os diferentes departamentos de um hospital.

Uma oportunidade de participação na discussão surge quando se examina se realmente as linhas de pesquisa que adotam a mudança conceitual concebem sua unidade de análise como mentes individuais. A argumentação contra Treagust e Duit é convincente porque o fato de Dana concordar com o entrevistador a respeito de uma analogia apresentada anteriormente em sala de aula permite um espectro variado de interpretações e muito pouco se pode concluir acerca do que ela realmente teria aprendido ali. Daí a fragilidade do exemplo fornecido.

Contudo, tomar a mente individual como unidade de análise não parece ser o propósito nem de Piaget nem das linhas de pesquisa inseridas no paradigma 
da mudança conceitual inspiradas em Vygotsky. $\mathrm{O}$ método clínico proposto por Piaget consistia em oferecer aos sujeitos pesquisados desafios lógicos envolvendo algum conceito e, posteriormente, analisar as respostas obtidas. Qualitativamente, agrupavam-se as respostas, tanto aquelas tidas como certas como aquelas erradas. Respostas erradas eram categorizadas conforme o erro cometido, ou conforme a aproximação da resposta considerada correta. Quantitativamente, verificavam-se as porcentagens de respostas de cada tipo presentes nos variados estágios de desenvolvimento dos sujeitos.

O procedimento como um todo permitia que se fizessem algumas inferências acerca dos caminhos trilhados pelos sujeitos enquanto evoluíam no entendimento de conceitos. Não se examinava uma resposta de um indivíduo somente, não se apontava para o momento em que um sujeito em especial teria evoluído de um estágio de desenvolvimento para outro; Piaget não se iludiu a esse respeito. A unidade de análise não parece ser a mente de um indivíduo qualquer, mas os padrões de respostas fornecidas de acordo com as condições configuradas pela pesquisa. Piaget procurou generalizar a maneira como o desenvolvimento ocorre e, nesse sentido, descreveu realmente processos que seriam experimentados por um sujeito ideal enquanto evoluiria de um estágio de desenvolvimento para outro. E não cabe confundir o objeto da generalização com a unidade de análise na pesquisa.

A questão que se coloca a seguir consiste em saber se linhas inspiradas em Vygotsky incluídas no paradigma da mudança conceitual têm mentes individuais como unidade de análise. $\mathrm{O}$ trecho de um artigo vale como ilustrativo da perspectiva de autores citados por Treagust e Duit:

Os significados são vistos como polissêmicos e polifônicos, criados na interação social e então internalizados pelos indivíduos. Além disso, o processo de aprendizagem não é visto como a substituição das velhas concepções, que o indivíduo já possui antes do processo de ensino, pelos novos conceitos científicos, mas como a negociação de novos significados num espaço comunicativo no qual há o encontro entre diferentes perspectivas culturais, num processo de crescimento mútuo. As interações discursivas são consideradas como constituintes do processo de construção de significados. (Mortimer; Scott, 2002, p. 284)

Esses pesquisadores analisam os diálogos, categorizando-os conforme a relação entre atores tenda a ser mais aberta ou mais diretiva, democrática ou autoritária. Um objetivo consiste em verificar como o professor, ou mesmo um grupo de alunos, vai controlando as interações no intuito de fazer com que os discursos dos alunos se aproximem cada vez mais do que se entende como discurso científico oficial.

Mortimer e Scott frisam a ideia de que os indivíduos não abrem mão de suas velhas concepções, trocando-as pelos conceitos científicos, mas negociam suas perspectivas com aquela a ser adotada no ambiente escolar. Parecem concordar com Roth e Law no que diz respeito ao papel do ambiente cultural na significação de um conceito quando afirmam que interações discursivas constituem processos de produção de significados.

Mortimer e Scott podem ter problemas em apresentar evidências da ocorrência da internalização de conceitos pelos indivíduos em tempo real. Podem, ainda, 
ter dificuldades em associar empiricamente uma categoria de discurso a uma maior ou menor oportunidade de aprendizagem por ela produzida. Como demonstrar, por exemplo, que um discurso autoritário do professor tende a produzir tal ou qual efeito sobre a aprendizagem? Todavia, acusá-los de tomar mentes individuais como unidades de análise parece fora de cogitação; eles analisam interações discursivas.

Roth destaca a impossibilidade de seus oponentes mostrarem uma mudança conceitual por meio da análise de discursos. Menciona, inclusive, um trabalho que desenvolveu com Duit, no qual o desafiou a apontar o momento de ocorrência de uma mudança conceitual em qualquer das transcrições obtidas (Roth; Duit, 2003). Duit não teria sido capaz de resolver o desafio satisfatoriamente. Roth infere que a análise de discurso poderia ser utilizada para se apontar inequivocamente uma mudança conceitual caso ela existisse.

Entendemos, contudo, que esse argumento não procede. Para se flagrar diretamente, e indubitavelmente, uma mudança conceitual durante um discurso, seria necessário que o sujeito que operasse tal mudança falasse sobre ela em um exercício de metacognição, a partir de uma observação da evolução do próprio pensamento. Em tempo real, isso é impossível. Ninguém consegue pensar e, ao mesmo tempo, observar o próprio pensamento. Qualquer indivíduo que tente acompanhar o próprio pensamento tem de fazê-lo a posteriori, mediante esforço mnemônico (Steiner, 1915/2000, p. 33). Como a memória é seletiva e tende a distorcer os fatos, nenhuma descrição de pensamento fornecida por um sujeito seria suficiente para a produção da prova pretendida.

\section{UMA POSIÇÃO EMBASADA NA PRÁTICA DOCENTE}

Pensamos a prática docente, planejamento e aulas, como campo empírico por excelência. No planejamento, lida-se com possibilidades; os professores se baseiam em expectativas acerca de como os alunos deverão responder a uma proposta qualquer. Tais expectativas, mesmo baseadas em experiências anteriores, existem apenas como abstrações. Nas aulas, a abstração transforma-se em expressão concreta, influenciada por uma série inumerável de fatores. Desde a maneira como a proposta é endereçada ao grupo, passando pelas condições de trabalho do professor, por suas crenças particulares, até as condições emocionais e situação social de cada aluno, tudo contribui para constituir um campo de determinações dos resultados.

Como mencionado anteriormente, as professoras optaram por seguir as orientações curriculares a que estavam acostumadas. Isso significa que havia uma estrutura preestabelecida, a qual tinha de ser contemplada. Em contrapartida, estava aberta a possibilidade de se criar estratégias de ensino negociadas no grupo.

A atividade sobre geometria foi dividida em unidades, cada uma equivalente a uma aula com objetivos próprios. A sequência das aulas sofreu adaptações decididas conforme o grupo de professores avaliava o desempenho dos alunos. Nesse sentido, o grupo agiu em parte dentro de um planejamento definido previamente e, ao mesmo tempo, adaptando-o conforme os resultados obtidos em cada aula. Todavia, estava implícito o objetivo de produzir aprendizagens. Aí reside um desafio significativo para a pesquisa. Para além daquilo que estava proposto, ou seja, das 
habilidades relacionadas ao campo da geometria, seria necessário verificar o que realmente estava acontecendo não somente com os alunos, mas também com os professores, um campo aberto a explorações.

Se o debate entre a mudança conceitual e a abordagem histórico-cultural for traduzido, mesmo que superficialmente, no que se refere a uma discussão entre a possibilidade de entender a aprendizagem como minimamente estruturada e previsível de um lado, e aberta e surpreendente de outro, a pesquisa propõe uma convivência de dois elementos que se contradizem. Significa considerar que duas perspectivas podem se sobrepor, reconhecendo-se que cada uma oferece uma descrição ao mesmo tempo factível e incompleta da realidade.

Quando se analisa o trabalho do professor, não um trabalho ideal qualquer, mas aquele estabelecido a partir de características histórica e socialmente situadas, com suas demandas típicas, emergem duas tendências simultaneamente: a necessidade desse profissional de recorrer constantemente a uma referência estruturada e, ao mesmo tempo, a importância de reconhecer que os resultados de cada evento são imprevisíveis e, pelo menos em parte, incontroláveis. Sendo assim, a aprendizagem tem um direcionamento determinado, e ao mesmo tempo reserva surpresas.

A preparação do plano de aulas revelou o lado estruturado do trabalho. Passaremos, então, à descrição de uma aula na qual se verificou a necessidade de uma melhor compreensão dos processos cognitivos vivenciados pelos alunos ao lado da ocorrência de singularidades que dificilmente se reproduziriam.

\section{ENFRENTAMENTO DE UM DESAFIO}

Em 24 de agosto de 2011, os alunos da professora Jussara foram desafiados a descobrir as onze planificações possíveis do cubo. Jussara, Denise e Alexandre, que compartilharam a posição de professor, combinaram que este último iria introduzir o desafio ao grupo de alunos. Ajudado por Jussara, Alexandre iniciou uma pequena explanação discutindo o que seriam sólidos, o cubo, e o que seria uma planificação, definições supostamente já familiares para a maioria da turma. Em seguida, foram apresentadas algumas regras e foi proposta aos alunos uma estratégia que ajudaria a solucionar o desafio.

O professor desenhou duas planificações com seis quadrados na lousa, uma que resultaria no cubo e uma falsa (Figura 1). Em 05:05 (tempo após começo da gravação em minutos e segundos), os alunos discutiram sobre os desenhos. Eles concordaram que a planificação de cima (verdadeira) resultaria em um cubo. Houve discordâncias quanto à planificação de baixo. Alexandre apresentou para a turma a planificação de cima recortada em papel, de tamanho bastante reduzido, com quadrados em torno de $1 \mathrm{~cm}$ de lado. Desse modo, estava propondo uma técnica para se proceder ao exame de qualquer ideia de planificação. Tal técnica consistiria em fazer o desenho em miniatura, recortar e testar o resultado fazendo as devidas dobras. Desenhando as planificações em miniatura, os alunos não teriam de recortar grandes porções de papel, o que tomaria um tempo razoável para a realização de cada teste.

A planificação correta recebeu o número 1 . Em seguida, foi verificada a planificação incorreta por meio de uma miniatura em papel previamente recortada. 
Constatada a impossibilidade de se fazer um cubo com aquela planificação, ela recebeu o número 1 seguido do sinal negativo. Outra planificação correta foi desenhada no quadro, apenas para chamar a atenção dos alunos para o fato de que ela era apenas uma rotação da primeira; portanto, não seria aceita como novidade. Com isso, antecipou-se uma regra que se mostrara necessária na experiência realizada em 2005 , enquanto os alunos trabalhavam na mesma tarefa. Naquela ocasião, também surgiu a necessidade de desqualificar como novidade uma planificação que fosse simétrica de outra. Contudo, os professores não quiseram introduzir a regra em relação a planificações simétricas no início da aula porque consideraram que seria bastante abstrata para os alunos que ainda nem tinham iniciado a investigação.

Ficou estabelecido que a lousa seria utilizada para registrar as descobertas, tanto as positivas quanto as negativas. À medida que fossem surgindo, seriam numeradas; as negativas indicadas pelo sinal característico. Como última regra, Alexandre desenhou no quadro uma suposta planificação na qual alguns quadrados se tocavam apenas nos vértices. Avisou que tal tipo de desenho não seria aceito como planificação.

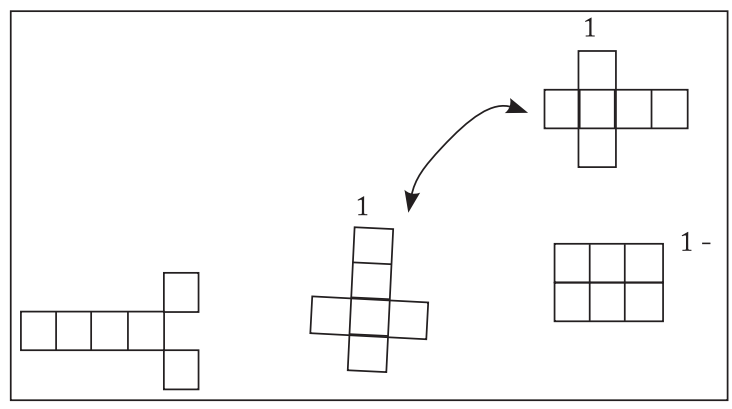

Figura 1 - Desenhos utilizados na apresentação do desafio.

As explicações iniciais duraram exatamente dez minutos. Houve um intervalo para o recreio e a turma voltou, agora organizada em dois grupos de seis alunos. $\mathrm{Du}-$ rante algum tempo, cada aluno estudou as possibilidades de novas planificações ainda sem estabelecer contato com os demais. Enquanto isso, Jussara, Denise e Alexandre distribuíram-se entre as carteiras, observando as produções, fazendo perguntas e, eventualmente, conferindo os trabalhos ou encorajando os alunos a registrarem suas propostas na lousa. As primeiras tentativas apenas reproduziram a planificação que já estava no quadro, aquela associada ao número 1 . Em 16:33, Leila anunciou que teria encontrado a segunda planificação. Concomitantemente, um colega anunciou que também teria descoberto uma planificação. Leila foi orientada a fazer o desenho de sua proposta na lousa, enquanto Jussara pediu ao aluno que verificasse se sua planificação seria a mesma proposta por Leila. Em 17:55, ela voltou para a carteira depois de terminar seu desenho na lousa. Ela escreveu o número 2 em sua planificação, mas Alexandre alertou o grupo para o fato de ainda não se ter uma comprovação de que aquela seria uma planificação válida. Na verdade, a planificação de Leila permite que se obtenha uma figura tridimensional com a aparência de um cubo, mas com dois quadrados sobrepondo-se no que deveria ser uma face (Figura 2). 


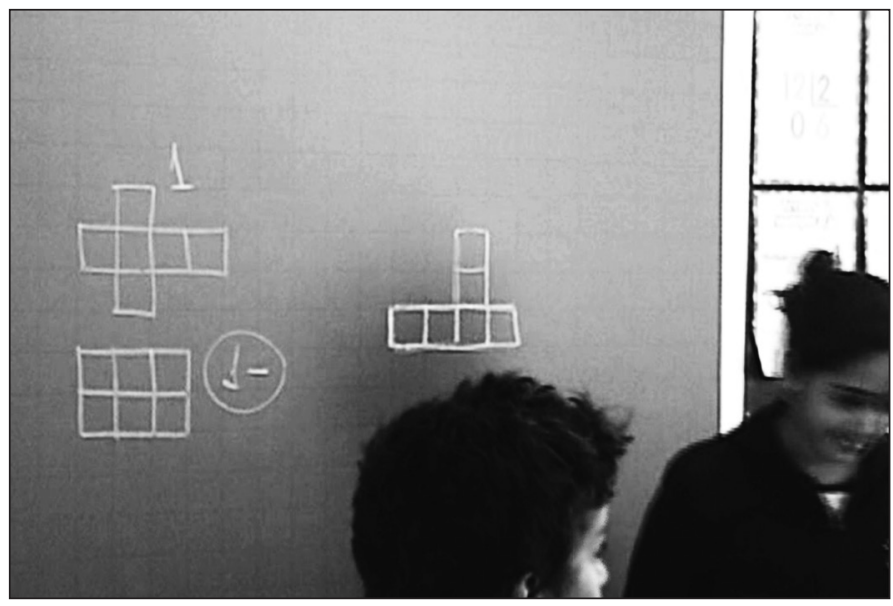

Figura 2 - Registro de Leila na lousa.

Até 22:30, portanto passados aproximadamente treze minutos de tentativas, os alunos haviam encontrado apenas uma segunda planificação verdadeira, cujo desenho é parecido com a primeira. Durante esse período, quatro propostas registradas no vídeo foram recusadas pelos professores porque todas eram rotações da planificação número 1. Jussara observou que Joana fez um desenho com inúmeros retângulos. Nas Figuras 3A e 3B, observa-se que há um recorte na folha de Joana que reproduz a forma da planificação 1 . Depois de comentar o desenho com Alexandre, Jussara chamou a atenção da menina dizendo que ela deveria desenhar apenas seis quadrados.

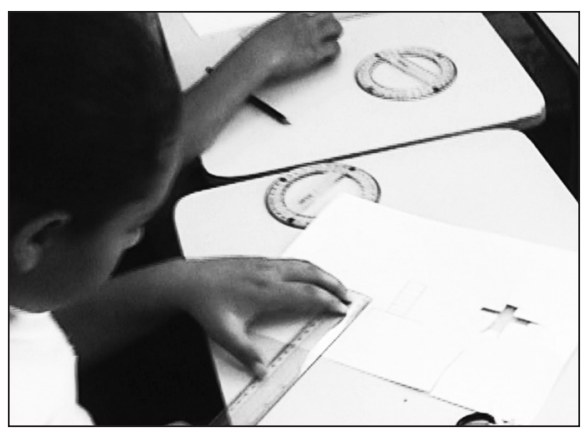

Figura 3A

Folha de trabalho de Joana.

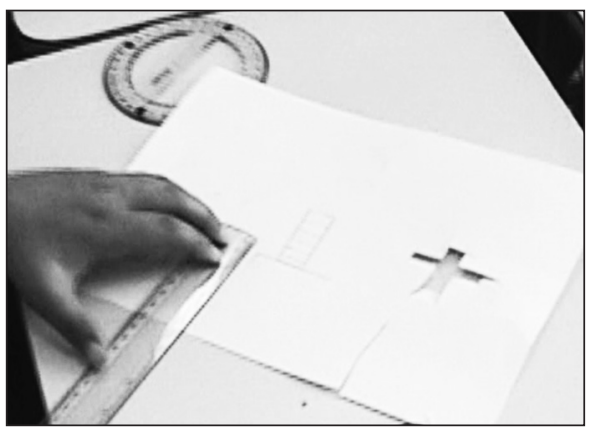

Figura 3B

Em 23:20, Leila anunciou que teria descoberto uma planificação correta. Orientada pelos professores, foi ao quadro verificar se ela repetia alguma que já 
tinha sido apresentada lá. De fato, havia reproduzido a planificação número 1 mais uma vez. Enquanto isso, a professora Denise se aproximou de Joana e iniciou um diálogo, tentando convencer a aluna de que era preciso desenhar quadrados, e apenas seis. Tentando clarear sua mensagem, Denise cortou seis quadrados no papel e os colocou sobre a mesa ao lado da aluna, compondo uma planificação que ainda não havia sido descoberta pela turma (Figura 4A). Aparentemente, depois de se certificar de que a aluna observara sua composição, Denise recolheu os quadrados e instruiu Joana a fazer um desenho como aquele. Dirigiu-se, em seguida, a Pedro, que se sentava ao lado de Joana, usando os mesmos seis quadrados de papel na tentativa de mostrar como iria ficar a figura tridimensional proposta pelo menino depois de dobrada a planificação. Denise anunciou a Pedro a necessidade de mudar a posição relativa de um dos quadrados de seu desenho para, assim, obter uma planificação correta. Denise até mesmo fez uma composição com seus quadrados explicitando a mudança de lugar do quadrado (Figura 4B). Pedro observou a composição de Denise e seguiu-se o diálogo:

Episódio 1

1. Pedro (apontando para o quadro): Mas aí vai ficar igual aquele ali ó.

2. Denise: Uai, não estou vendo ele no quadro não. Onde que ele está?

3. Pedro (sorrindo): Vou ter que fazer outro agora.

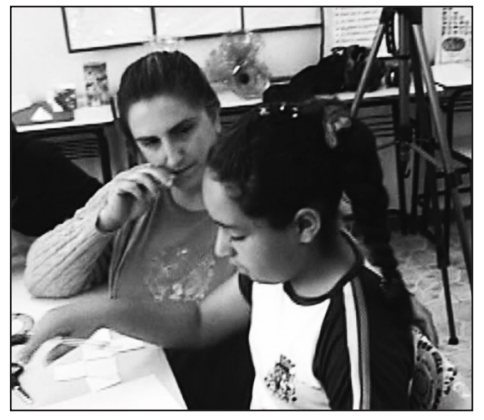

Figura 4A

Denise interfere nos trabalhos de Joana e de Pedro

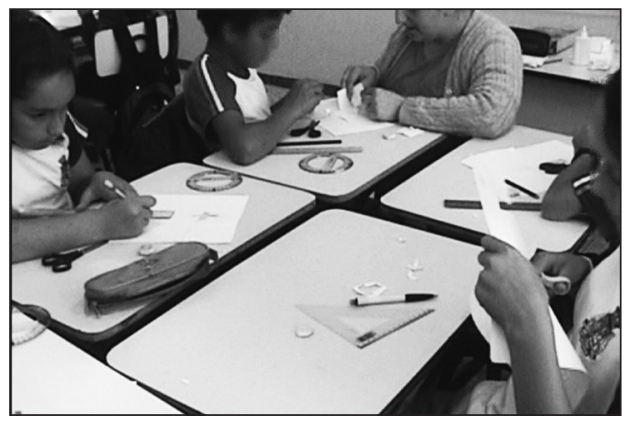

Figura 4B

Em 29:02, a aluna Teresa registrou no quadro a planificação de número 4 negativa. Até aquele momento, havia apenas 3 positivas. Surgiram ainda algumas planificações que repetiam a planificação 1 positiva e a planificação 1 negativa. Em 31:35, Leo experimentou desenhar e recortar seis quadrados. Então passou a estudar possibilidades de montar os seis quadrados, uma vez que podia movê-los livremente. Não há registro de Leo conversando com Denise, mas é provável que ele tenha se inspirado no fato de a professora usar seis quadrados de papel enquanto abordava os alunos. Naquele momento, ele inaugurou uma nova técnica de investigação que rapidamente foi adotada por vários outros colegas. A maioria da turma deixou de desenhar miniaturas das planificações pensadas e passou a estudar composições com seis quadrados recortados separadamente. Enquanto Leo experimentava sua 
nova técnica, Pedro registrou na lousa a planificação positiva de número 4, que lhe fora sugerida por Denise.

Em 34:00, Denise voltou a se aproximar de Joana. Dessa vez, a professora produziu uma planificação que supostamente estaria reproduzindo um desenho da aluna (Figura 5A). Joana foi à lousa para comparar tal proposta com outras ali desenhadas. Para isso, levou consigo a planificação representada pelos quadrados de papel, unidos por Denise com fita adesiva. No entanto, quando tentou contrapor essa planificação com um desenho da lousa, uma parte da planificação separou-se com o rompimento da fita adesiva (Figura 5B). Joana foi instruída a retornar à sua carteira e refazer a emenda. Mas ela não mais trabalhou nessa planificação e voltou a se ocupar com seus desenhos.

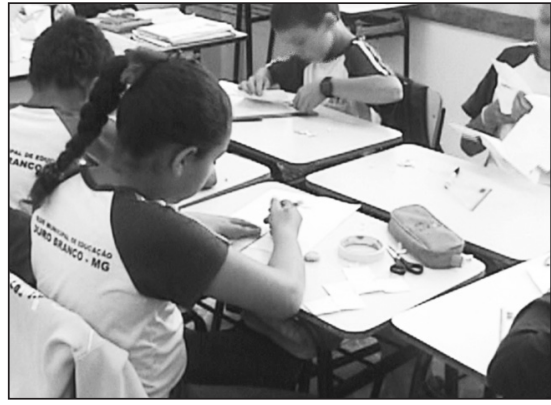

Figura 5A

Joana tenta desenhar a planificação sugerida por Denise.

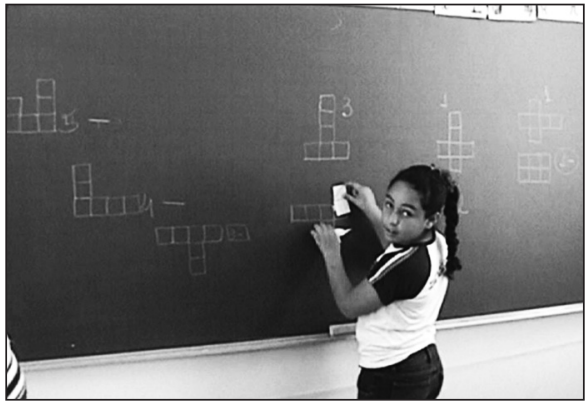

Figura 5B

A aula seguiu com alunos tentando novas planificações enquanto os professores foram orientando a comparação de cada nova proposta com aquelas desenhadas na lousa. Nesse processo, surgiu a necessidade de se verificar se cada proposta candidata seria simétrica de uma já desenhada. Aos poucos, alguns alunos foram assumindo a tarefa de verificar em primeira mão se haviam produzido uma novidade ou não. À medida que se convenciam de estar de posse de uma produção inédita, entregavam a planificação a um dos professores e pediam para conferir o resultado. A planificação correta de número 9 foi registrada depois de uma hora de gravação (Figuras 6A, 6B, 6C e 6D).

Como faltavam apenas duas planificações, a descoberta de uma novidade se tornava mais difícil. Então, cada vez que alguém apresentava uma proposta, um grupo ia com a professora conferir se valeria como uma nova planificação positiva ou não. Enquanto isso, Joana trabalhava individualmente. Em 1:02:29, a câmera mostra uma das inúmeras tentativas da aluna, logo após ela ser repreendida por Jussara (Figura 7A). A professora disse a Joana que ela deveria fazer um desenho utilizando apenas seis quadrados. A partir desse momento, Joana voltou a fazer uma planificação em miniatura, mas agora seu desenho continha os seis quadrados, como the fora indicado. Joana terminou o desenho, recortou, experimentou dobrá-lo e o deixou de lado, iniciando logo outro desenho. Recortou novamente e, em 1:08:20, Jussara percebeu que havia alguma novidade na proposta de Joana e seguiu-se um diálogo entre as duas (Figura 7B): 


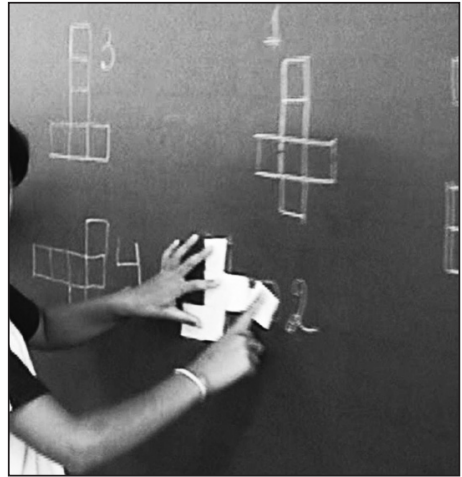

Figura 6A

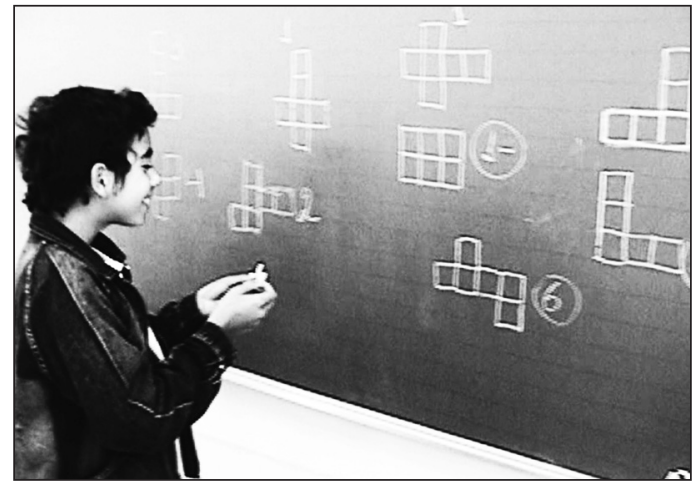

Figura 6B

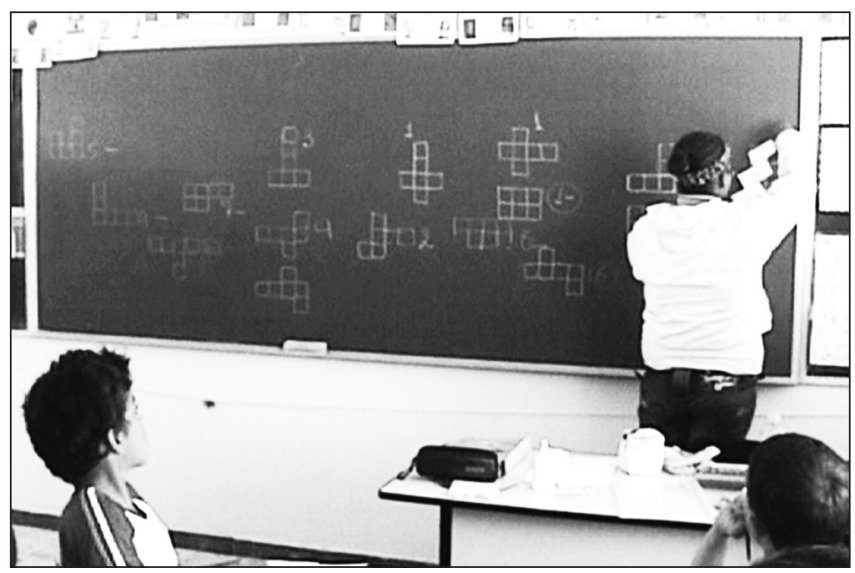

Figura 6C

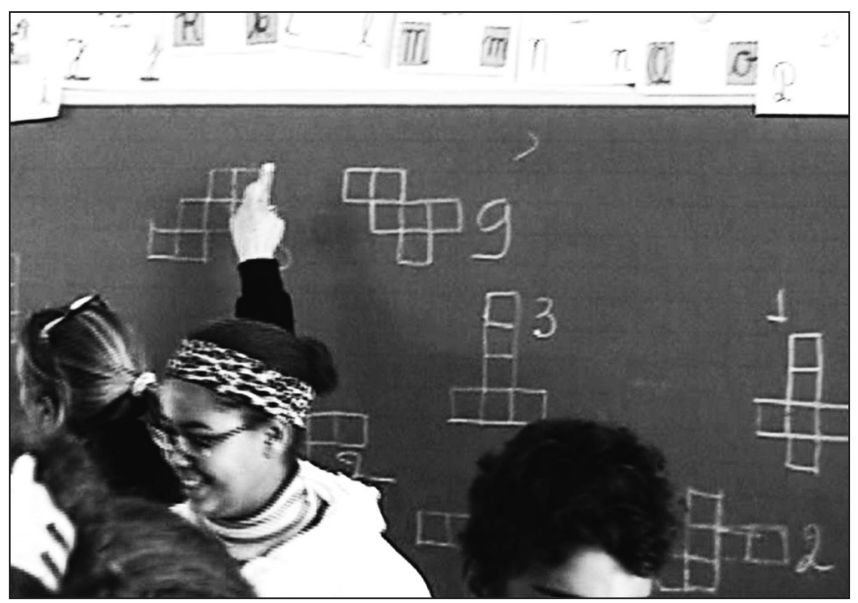

Figura 6D

Evolução das planificações descobertas. 
Episódio 2

1. Jussara: Ela fez diferente. Não sei se vai fechar.

2. Joana: Não fecha.

3. Jussara: Uai, você não sabe. Dobrou tudo?

4. Joana: Dobrei.

Jussara chamou os alunos para ajudarem a conferir a proposta de Joana, no que foi atendida por Alírio. Ao mesmo tempo, a professora providenciou seis quadrados de papel e os colocou na posição correspondente ao desenho. Alírio comprovou que a planificação em miniatura fechava em um cubo (Figura 7C), mas Jussara pediu a Alexandre que desse sua opinião. Alexandre confirmou a novidade; estava assim descoberta a décima planificação, a qual Joana registrou na lousa (Figura 7D).

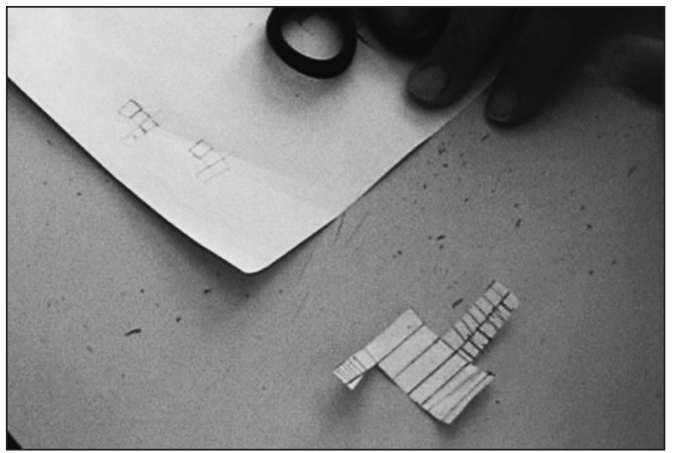

Figura 7A

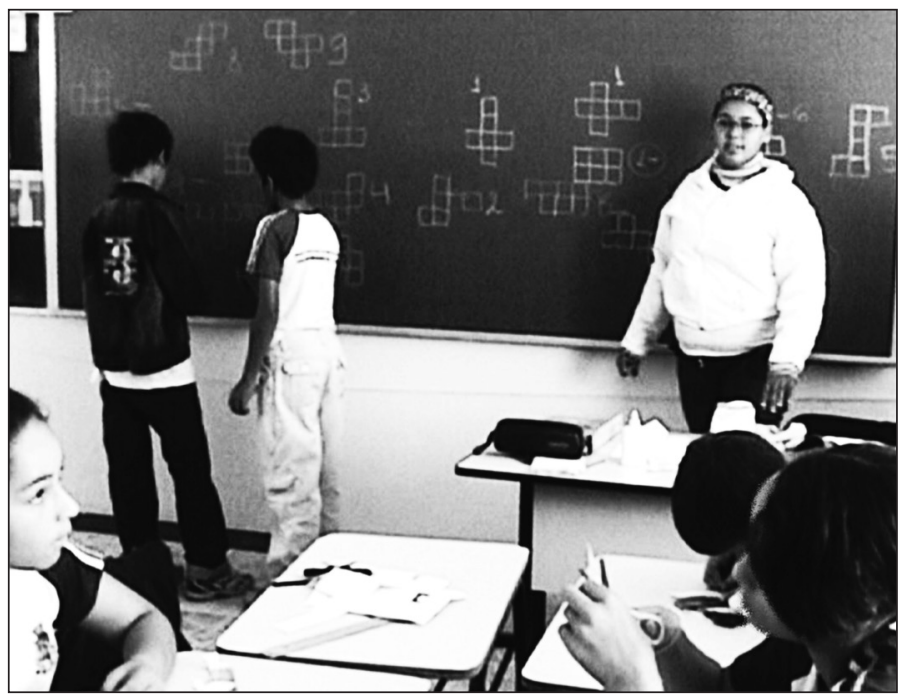

Figura 7B 


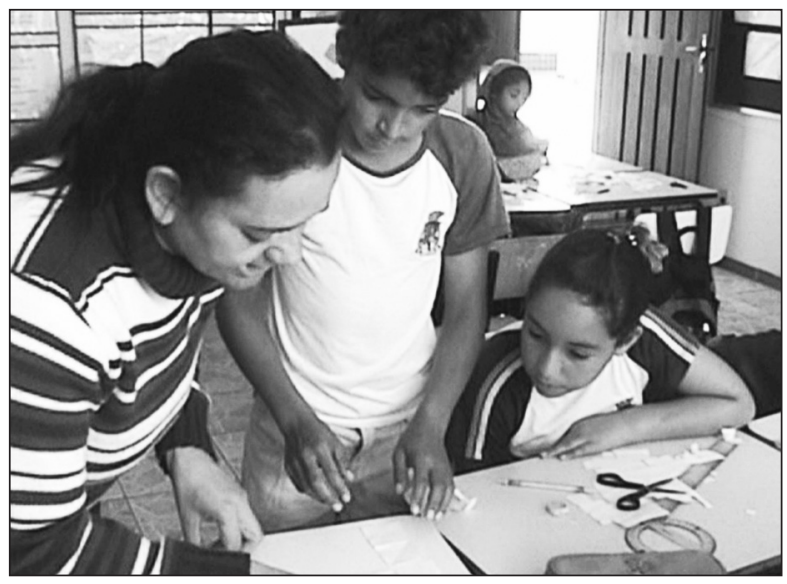

Figura 7C

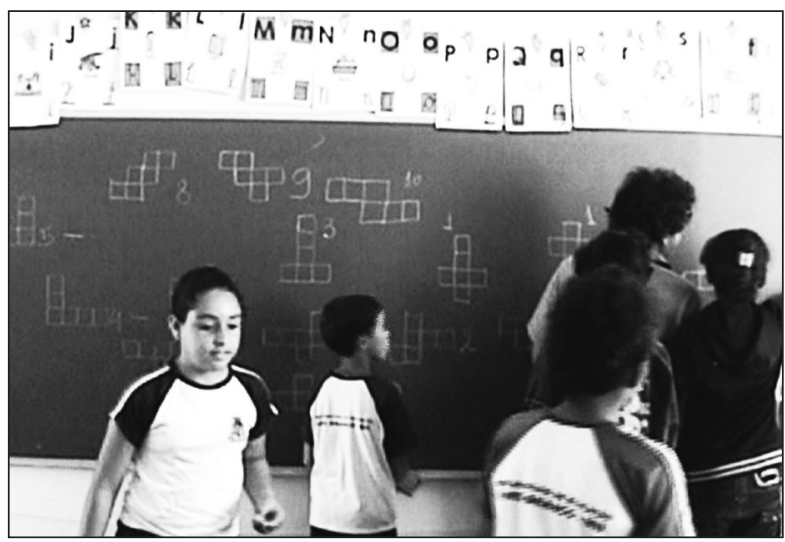

Figura 7D

Joana descobre e desenha a décima planificação.

Houve ainda quatro tentativas frustradas de se produzir a décima primeira planificação. Em todos os casos, vários alunos e alunas se aglomeravam ao lado da lousa enquanto os professores testavam a nova proposta. Até que, em 1:15:10, ficou confirmada a descoberta de Cláudio como a última das planificações do cubo. Essa fora a terceira contribuição bem-sucedida desse aluno para a consecução da tarefa.

\section{QUESTÕES QUE EMERGEM DA ATIVIDADE}

Anunciamos a existência de um debate entre correntes de pensadores que procuram entender a aprendizagem, no qual destacamos dois paradigmas. Um deles, aquele associado à mudança conceitual, apresenta-se dividido em duas vertentes, com diferenças na interpretação de como essa mudança ocorreria. Em oposição, o segundo paradigma assume as consequências últimas da condição situada das ações humanas, nega a possibilidade de uma apreensão e generalização confiável na 
maneira como os sujeitos aprendem; nega a própria existência da mudança conceitual. Referenciando-nos nesse debate, preconizamos a possibilidade de coexistência desses paradigmas e, mais que isso, a possibilidade de que as três perspectivas mencionadas promovam uma melhor compreensão da prática educativa sem que se excluam necessariamente. Cabe-nos, portanto, a tarefa de indicar como nosso posicionamento se expressa em uma situação empírica como a aula aqui descrita.

O desempenho de Joana, por exemplo, suscita questões que poderiam ser investigadas por um olhar sobre o desenvolvimento da capacidade de compreender e produzir planificações. Desde a introdução da tarefa, no início da aula, foi anunciado que seriam necessários seis quadrados para a planificação do cubo. Foram feitos até mesmo dois desenhos no quadro, ambos compostos por seis quadrados. No entanto, no episódio representado pela Figura 3, nota-se que a aluna produziu um retângulo dividido em seis partes e está desenhando um outro retângulo perpendicular ao primeiro.

A produção de Joana exibida na Figura 7A é ainda mais surpreendente. Ali se veem dois retângulos adjacentes divididos em sete partes, ligados a outros sete retângulos alinhados e ainda um último retângulo alinhado a essa fileira e dividido em sete partes desiguais. Quando produziu esse desenho, Joana já havia sofrido duas intervenções de Denise, e em ambas a professora the mostrou como poderia ser produzida uma planificação do cubo. Na segunda intervenção, Denise entregou a planificação pronta com os quadrados unidos por fita adesiva (Figura 5A). Apesar do esforço da professora, parece que Joana simplesmente não conseguiu perceber a relação entre o número de quadrados e o resultado da planificação. Parece que adotou uma hipótese e persistiu nela por mais de uma hora de trabalho. Quando finalmente acatou a ordem de Jussara, que lhe indicou quantos quadrados deveria desenhar, Joana fez um desenho, recortou e não se convenceu de que ali estava uma planificação correta. Ela afirmou que sua planificação não fechava (episódio 2, turno 3). No entanto, além de produzir o cubo, a planificação era inédita para a turma.

Em Soares (2009,p. 150 e seguintes) encontra-se a descrição da performance de um aluno na mesma faixa etária de Joana, também apresentando dificuldades bastante acentuadas quando enfrenta o desafio de produzir uma planificação. Esses casos sugerem investigações sobre como se desenvolve a habilidade de compreender a produção de um desenho em duas dimensões e sua transformação em um objeto de três dimensões. Tais investigações poderiam determinar diferentes níveis de dificuldade e até mesmo a persistência e gradual superação dessas dificuldades, a partir da comparação de desempenhos de sujeitos conforme supostos estágios de desenvolvimento da capacidade de processar a planificação. Resultados de tais investigações poderiam colaborar para que a maneira de tratar o desafio adotada por Joana fosse mais bem compreendida. Poder-se-ia ampliar a capacidade de compreensão dos professores sobre dificuldades semelhantes à da aluna, ou mesmo outras dificuldades menos acentuadas.

Joana deixa-nos também com perguntas acerca do que teria aprendido nessa aula. Será que não seguiu as instruções de Denise porque não conseguiu compreender o que a professora lhe oferecia? Por que mudou seu desenho, passando a fazer seis quadrados depois da segunda intervenção de Jussara? O que o fato de 
obter sucesso finalmente significaria para o desenvolvimento da aluna? Será que sua conquista, aparentemente forçada pela intervenção de Jussara, provocou uma mudança na sua maneira de perceber a planificação?

A intervenção de Denise no trabalho de Pedro levou a um resultado diferente daquele que a professora obteve com Joana. A partir da afirmação do aluno (episódio 1, turno 3) e considerando-se seu desenho na lousa pouco tempo depois, é possível inferir que ele estava em outro nível de compreensão quando comparado com Joana. Denise partiu de uma produção de Pedro com seis quadrados, mostrou a ele o resultado da dobra da sua proposta e o erro no qual incorria. Sugeriu uma troca de posição de um dos quadrados, o que resultaria em uma planificação positiva inédita. Pedro acatou a sugestão da professora.

A indicação para ser a lousa o espaço de registro das descobertas foi decidida pelos professores no planejamento da aula. Da mesma maneira, a sugestão da técnica de se desenhar as planificações em miniatura. As decisões do planejamento basearam-se no trabalho semelhante realizado em 2005. Nessa experiência anterior, os alunos iniciaram a aula trabalhando em grupos isolados uns dos outros. Em dado momento, a professora da turma registrou na lousa algumas planificações que já haviam sido descobertas. Essa atitude mudou o rumo da aula, uma vez que a lousa tornou-se um suporte para a comunicação de todos, produzindo-se uma dinâmica de trabalho coletivo com grande participação dos alunos na percepção dos professores.

Em ambos os experimentos, verificou-se que alguns alunos agiram de maneira empreendedora, procurando produzir novidades, insistindo em propor novas planificações, mesmo depois de frustrarem-se em alguns resultados em virtude da repetição de desenhos já registrados. Verificou-se também que alguns alunos assumiram a tarefa de investigar novas propostas, agindo como guardiões da legitimidade do processo. Outros alunos associaram-se, especialmente em duplas, quando uniam esforços no enfrentamento do desafio. Na percepção dos professores, na turma de Jussara, em dado momento, instalou-se um clima de competição. Quando a última planificação foi descoberta, a euforia de cumprimento da tarefa misturou-se a um certo sentimento de decepção expresso por alguns alunos, que argumentaram que gostariam de estar no lugar daquele que concluiu o desafio. Na avaliação dos professores, a turma agiu com aparente ambiguidade entre cooperação e competição.

Existe, portanto, uma percepção de que a utilização da lousa como suporte para as produções coletivas modifica qualitativamente a dinâmica das interações na atividade. No entanto, permanecem questões que demandam investigações mais acuradas, as quais poderiam ser levadas adiante com auxílio do paradigma da mudança conceitual em linhas inspiradas em Vygotsky. Como ocorrem trocas de saberes entre alunos quando a lousa promove uma comunicação coletiva? Que efeitos poderiam ser observados considerando as diferentes participações de cada um? Poder-se-ia falar em aprendizagem diferenciada quando se compara, por exemplo, os guardiões com os empreendedores? Que diferenças poderiam ser generalizadas quando a tarefa é desenvolvida com ou sem tal suporte? Como as interferências dos professores se refletem nas atitudes dos alunos?

$\mathrm{O}$ tratamento das questões emergentes de uma situação empírica como a aqui discutida pode oferecer uma ampliação da percepção das situações reais e uma 
maior precisão na análise dos acontecimentos. Com um conhecimento acerca dos efeitos esperados das interações entre atores, pode-se configurar o ambiente de maneira que equilibre momentos em que os alunos são convidados a explorar suas ideias com momentos nos quais compartilham as ideias com os colegas, avaliando-as e aperfeiçoando-as. Se o professor detém o conhecimento de como evolui o pensamento sobre a planificação, pode ter uma noção de alternativas de ação diante de dificuldades como as apresentadas por Joana. O conhecimento acerca de como intervir também se expande quando se dispõe de análises de interações entre professores e alunos. Como avaliar, por exemplo, a diferença da intervenção quando se aborda um aluno com grande dificuldade de compreensão da tarefa e outro que compreende melhor o que está em jogo?

As investigações sugeridas podem contribuir para o aprimoramento da prática docente. Contudo, mesmo que as questões antes citadas fossem exaustivamente investigadas, mesmo com um acúmulo de generalizações obtidas de experiências diversificadas, a realidade sempre oferece elementos não replicáveis. Cada evento tem uma quantidade inumerável de fatores que o influenciam, o que garante a presença constante da novidade no horizonte da atividade.

$\mathrm{O}$ reconhecimento do valor dos diversos saberes demandados pela atividade tem correspondência no debate sobre os paradigmas ocupados com questões relativas à aprendizagem. Se se aceita que os diferentes olhares sobre a aprendizagem oferecem possibilidades de aperfeiçoamento da prática docente, é forçoso reconhecer que a correspondência com necessidades de conhecimento percebidas nos ambientes escolares aponta para uma convivência dos paradigmas, pelo menos no âmbito dessa prática. Cabe expor, portanto, como os paradigmas podem contribuir para o desenvolvimento da práxis, cada qual apresentando limitações e mantendo seus princípios.

\section{ONDE EMBASAR A CONVIVÊNCIA DE PARADIGMAS EM DISPUTA}

Imaginamos que questões relativas à compreensão dos processos cognitivos envolvidos na planificação poderiam ser investigadas por referenciais teóricos baseados em Piaget. Isso significa que as investigações seriam conduzidas por meio de desafios oferecidos a uma quantidade razoável de sujeitos em faixas etárias diferentes e em ambientes especialmente preparados para que pudessem expressar suas ideias sem interferência de terceiros. Desafios seriam ordenados dos mais simples aos mais complexos, direcionados no intuito de se testar capacidades, como a de imaginar o resultado obtido da dobra de uma planificação, imaginar a planificação de um sólido dado, imaginar variações em planificações de um mesmo sólido etc. Análises de tais experimentos procurariam por padrões nas respostas dos sujeitos; erros cometidos poderiam sugerir a existência de estágios presentes no desenvolvimento da capacidade de planificar.

Uma investigação conduzida dessa maneira teria as limitações próprias dos trabalhos que isolam os indivíduos de interações rotineiras e desconsideram variações nos meios culturais de origem desses indivíduos. Esperar-se-ia que a pesquisa gerasse padrões de desenvolvimento de um sujeito ideal; padrões que descreveriam 
o que se poderia esperar de uma turma e não necessariamente o que realmente aconteceria com uma turma específica. Mesmo com essas limitações, tal pesquisa poderia colaborar com a prática docente em dois sentidos: forneceria dados a serem considerados nas decisões curriculares e auxiliaria um professor a compreender uma dificuldade de execução de uma tarefa dada.

Entendemos que uma perspectiva da mudança conceitual fundamentada em Vygotsky iria contribuir para se verificar efeitos das interações coletivas proporcionadas pela aula. Tal investigação ofereceria, por exemplo, análises dos resultados obtidos com a utilização da lousa como suporte para registro das descobertas da turma, assim como elementos para melhor compreender os efeitos das intervenções dos professores com os alunos e das interações entre os próprios alunos. Sabemos que os comportamentos dos alunos foram bastante diversificados. Alguns aparentemente tentaram resolver o desafio de maneira mais individual; outros se uniram a companheiros e compartilharam descobertas; outros ainda alternaram entre trabalhar individualmente e interagir com grupos de colegas. Percebemos certa competição na turma, cada qual, ou cada dupla, ou mesmo cada grupo, tentando marcar ponto com uma descoberta inédita, mas não temos uma noção mais precisa acerca do desenvolvimento proporcionado pelas interações aqui descritas, bem como pela instalação espontânea desse clima competitivo, se é que ele realmente pode ser confirmado.

Tal investigação das interações sob a perspectiva da mudança conceitual forneceria, na nossa expectativa, análises que indicariam como a aprendizagem pode ter sido potencializada, ou arrefecida, valendo-se das diversas modalidades de interação registradas. A história de Joana, por exemplo, é rica em exemplos de diferentes interferências de outras pessoas e requer uma melhor compreensão dos efeitos dessa ação sobre a aluna. Novamente, os resultados seriam tomados como indicações, possibilidades, expectativas, não como garantia de que se repetiriam em outras ocasiões. Mesmo considerando a relatividade dessas análises, elas colaborariam para se configurar novas experiências com a planificação, além de promover uma oportunidade para os professores refletirem sobre alternativas de intervenção nos trabalhos dos alunos.

A perspectiva histórico-cultural adotada por Roth alerta-nos para o caráter coletivo da aprendizagem e para a impossibilidade de se saber realmente o que cada participante da atividade incorporou em seu desenvolvimento. Podemos, por exemplo, testemunhar uma parte das ações de Joana e suas interações com a professora e colegas. Podemos também interpretar o conjunto de condições criadas pelas ações coletivas como a geração de possibilidades de desenvolvimento. Contudo, é preciso que se mantenha o discurso coerente com o que a realidade observada apresenta, evitando-se inferir dos fatos algo além do que eles realmente permitem afirmar. Isso implica a admissão de que não podemos postular qualquer mudança conceitual alcançada pela aluna.

Cada movimento observado durante a aula guarda uma singularidade, a qual merece ser assim considerada antes que se pretenda partir para generalizações. Além disso, é preciso ter em conta o fato de que a realidade da qual estamos falando está recortada pelo que foi acessado pelos aparelhos de áudio e vídeo e filtrada pelas 
percepções das pessoas que analisaram sons e imagens. A abordagem histórico-cultural presente no segundo paradigma se ajusta à perspectiva dialógica adotada na pesquisa em tela em virtude do movimento proposto ao grupo de professores. Tal movimento cíclico supõe planejamentos coletivos, compartilhamento da posição de professor e análise dos episódios. Espera-se que os participantes problematizem os eventos registrados, questionem e investiguem temas de importância reconhecida pelo grupo e procurem dialogar com pesquisadores a fim de expandir a capacidade de compreensão dos elementos envolvidos na prática docente.

A necessidade de entender melhor como se processa a aprendizagem e como as interações entre os sujeitos da atividade colaboram para o seu desenvolvimento adveio desse movimento da pesquisa. Retomando o ciclo, espera-se que os participantes retornem à sala de aula enriquecidos por uma práxis em constante renovação, cientes de que um olhar renovado permite que se amplie o espaço de manobra do professor, e cientes de que a realidade sempre será mais complexa que aquilo que se pode apreender e organizar em palavras.

Um ponto para se argumentar em favor da convivência das posições teóricas aqui apresentadas consiste na assunção das diferentes dimensões temporais associadas à prática do professor. Durante o planejamento, predomina o que Ricœur (1980) denomina o tempo da narrativa. Nessa dimensão temporal, o professor se apropria de saberes produzidos sobre como os alunos acessariam o tópico com o qual vai trabalhar. Tais saberes advêm de suas experiências profissionais e de narrativas sobre experiências realizadas em outros contextos, incluindo-se aí investigações sobre como os sujeitos evoluiriam em estágios de desenvolvimento, bem como narrativas de trabalhos em sala de aula, como aquela antes aqui exposta. Essas narrativas compõem um conjunto de saberes que estariam disponíveis ao professor e poderiam orientá-lo nas decisões relativas ao planejamento.

Enquanto planeja, portanto, o professor baseia-se em ideias gerais sobre como seus alunos tenderiam a se comportar para tomar decisões acerca de como irá propor o trabalho em sala de aula. Nesse momento, pode reavaliar cada ação proposta e rearticular as diversas ações conforme the parecer conveniente. Na possibilidade de refazer qualquer etapa do processo, verifica-se o caráter reversível próprio do tempo da narrativa, ou seja, a possibilidade de recompor mentalmente as etapas do trabalho conforme o interesse percebido pelo professor.

Durante a aula, a dimensão temporal prevalente não é mais o tempo da narrativa. Praticamente desaparece a possibilidade de se reverterem as decisões tomadas. Uma vez proposta uma ação, o professor provoca reações nos alunos e não mais controla como eles interagem com o que lhes foi apresentado. Nesse sentido, o professor e os alunos encontram-se imersos em uma atividade em andamento, em uma dimensão fenomenológica do tempo, na qual predomina a percepção daquilo que se apresenta no momento, aqui e agora. Os atores reagem continuamente às ações de uns sobre outros e, nesse sentido, deparam-se com novidades a todo momento. Lidam com elementos não previstos, e cada pessoa age conforme condições histórica e culturalmente situadas. O que acontece na sala de aula, levando-se em conta os detalhes de cada momento, não se repete, é irreversível por natureza. 
Em qualquer generalização que se proponha, decorrente de uma investigação sobre o desenvolvimento de um conceito ou da narrativa de episódios vivenciados, está presente a crença de que algo será recorrente em condições semelhantes àquelas investigadas. Necessariamente, uma generalização compõe-se de abstrações, o que, para a prática docente, pode ser interpretado como indicativo de expectativas do que pode ocorrer em determinadas circunstâncias. Por mais que se admita que generalizações são questionáveis e podem ser negadas em cada nova prática, elas têm papel importante como saberes disponíveis para a composição de planejamentos.

A convicção de que um professor pode tirar proveito de pesquisas baseadas na mudança conceitual advém do fato de que professores trabalham com conceitos definidos pelos currículos escolares. Nesse sentido, o trabalho docente tem alvos previamente definidos. Estamos cientes de que o ensino poderia ser conduzido de maneira diferente, até mesmo sem a divisão por disciplinas escolares, mas essa não é a realidade de nossas escolas. Então, como vislumbra o trabalho sobre um conceito, o professor pode valer-se do que pesquisas baseadas na mudança conceitual indicam. Ao mesmo tempo, reconhecemos que os acontecimentos na sala de aula são situados e irreversíveis. Podemos então apontar momentos diferentes do trabalho docente e associar a cada momento o que os paradigmas em disputa têm para oferecer ao profissional do ensino.

Nossa convicção da possibilidade de convivência dos paradigmas em disputa está baseada, portanto, no reconhecimento de que o professor experimenta dimensões temporais diferentes enquanto planeja e leciona, e que cada um desses momentos pode ser enriquecido por conhecimentos gerados em pesquisas com diferentes princípios e configurações.

\section{CONSIDERAÇÕES FINAIS}

Argumentamos em favor de uma convivência possível das concepções de aprendizagem em disputa. Reconhecemos que cada paradigma pode oferecer um alargamento da compreensão da realidade com a qual os professores se deparam em sua prática profissional, mesmo que cada um apresente limitações. Essa convivência torna-se possível se se toma a realidade como polissêmica, ou seja, os acontecimentos permitem interpretações com base em lógicas consistentes diversificadas. De cada ponto de vista que se observa e se discursa sobre os acontecimentos, emerge um quadro sempre inacabado e parcial da totalidade. Isso não quer dizer que as interpretações são igualmente válidas. Concordamos com Roth quando ele criticou a descrição da aluna Dana, proposta por Treagust e Duit, como exemplo de mudança conceitual. Indo adiante, reconhecemos que a mudança conceitual não é algo que se observa em tempo real, uma vez que as pessoas não conseguem descrever fielmente seus pensamentos.

Entendemos que toda interpretação que se apresenta deve passar por rigoroso teste crítico. No entanto, não estamos convencidos de que a mudança conceitual seria um conjunto de estruturas existentes apenas na mente de determinados pesquisadores, ou que os pesquisadores que nela acreditam têm a mente individual como unidade de análise. Do nosso ponto de vista, as contribuições do paradigma 
da mudança conceitual, seja de linhas referenciadas em Piaget ou Vygotsky, merecem ser consideradas quando emergem questões relativas à aprendizagem.

Uma abordagem que incorpora o que está previamente estruturado, além de suas possibilidades em aberto, as quais somente se definem nas ações concretas dos envolvidos, parece-nos a mais adequada para caracterizar nossas próprias convicções. No trabalho de campo, evidencia-se a novidade, uma vez que cada evento é singular. $\mathrm{Na}$ análise de episódios e no tratamento das questões emergentes, faz-se necessário ir em busca do que está registrado, tentativas de generalizações geradas a partir de experiências ocorridas em outras realidades. Do confronto entre novidades e generalizações, espera-se a criação de novas maneiras de perceber, interpretar e agir na sala de aula.

\section{REFERÊNCIAS}

Boylan, M. Ecologies of participation in school classrooms. Teaching and Teacher Education, San Francisco: Elsevier Education, n. 26, p. 61-70, Jan. 2010. Disponível em: <http://www.sciencedirect.com/science/article/pii/S0742051X09001656>. Acesso em: 27 dez. 2015.

Fernández, L. C.; Gatica, M. Q.; Blancafot, A. M. La importancia de la historia de la química en la enseñanza escolar: análisis del pensamiento y elaboración de material didáctico de profesores en formación. Ciência $\Xi$ Educação, Bauru: UNESP, v. 16, n. 2, p. 277-291, 2010. Disponível em: <http://www.scielo.br/scielo.php?script=sci_arttext \&pid=S1516-73132010000200001 >. Acesso em: 27 dez. 2015.

GaliLI, I. Promotion of cultural content knowledge through the use of the history and philosophy of science. Sicene E Education, Dordrecht: Springer, v. 21, n. 9, p.1.283-1.316, Sept.2011. Disponível em: <http://link.springer.com/article/10.1007\%2Fs11191-0119376-x>. Acesso em: 27 dez. 2015.

Goulart, M. I. M. A exploração do mundo físico pela criança: participação e aprendizagem. 2005. 272f. Tese (Doutorado em Educação) - Universidade Federal de Minas Gerais, Belo Horizonte, 2005.

LAw, J. After method: mess in social science research. London: Routledge, 2004.

Merenluoto, K.; Lehtinen, E. Conceptual change in mathematics: understanding the real numbers. In: Limón, M.; Mason, L. (Orgs.). Reconsidering conceptual change: issues in theory and practice. Dordrecht: Springer, 2002. p. 232-257. Disponível em: <http://www.springerlink.com/content/m135181214845242/>. Acesso em:27 dez. 2015.

Mortimer, E. F.; Scott, P. H. Atividades discursivas nas salas de aula de ciências: uma ferramenta sociocultural para analisar e planejar o ensino. Investigaçóes em Ensino de Ciências, Porto Alegre: UFRGS, v. 7, n. 3, p. 283-306, 2002. Disponível em: <http:// www.if.ufrgs.br/ienci/artigos/Artigo_ID94/v7_n3_a2002>. Acesso em: 27 dez. 2015.

Nicolli, A. A.; Mortimer, E. F. Perfil conceitual e a escolarização do conceito de morte no ensino de ciências. Educar em Revista, Curitiba: UFPR, v. 44, n. 2, p. 19-35, mar. 2012. Disponível em: <http://ojs.c3sl.ufpr.br/ojs-2.2.4/index.php/educar/article/ viewArticle/27868>. Acesso em: 27 dez. 2015. 
Oliveira, A. W. From professional development to classroom instruction: addressing issues related to science inquiry discourse. Cultural Studies of Science Education, Dordrecht: Springer, v. 4, n. 4, p. 865-873, Dec. 2009. Disponível em: <http://www. springerlink.com/content/t1455u524507x722/>. Acesso em: 27 dez. 2015.

Riccur, P. Narrative time. Critical Inquiry, Chicago: University of Chicago Press, v. 7, n. 1,p.169-190,1980. Disponível em: <http://www.jstor.org/stable/1343181?seq=1\#page_ scan_tab_contents>. Acesso em: 27 dez. 2015.

Rотн, W.-M. Being and becoming in the classroom. Westport, Connecticut; London: Ablex Publishing, 2002.

. A question of competing paradigms? Cultural Studies of Science Education, Dordrecht: Springer, v. 3, n. 2, p. 373-385, July 2008. Disponível em: <http://www. springerlink.com/content/t81q6vnr0v36613w/>. Acesso em: 27 dez. 2015.

Science of learning is learning of science: why we need a dialectical approach to science education research. Cultural Studies of Science Education, Dordrecht: Springer, v. 7, n. 2, p. 255-277, June 2012. Disponível em: <http://www.springerlink.com/ content/301742564m937458/>. Acesso em: 27 dez. 2015.

.; Duit, R. Emergence, flexibility, and stabilization of language in a physics classroom. Journal for Research in Science Teaching, New Jersey: Wiley, v. 40, n. 9, p. 869-897, Nov. 2003. Disponível em: <http://onlinelibrary.wiley.com/doi/10.1002/tea.10114/ abstract>. Acesso em: 27 dez. 2015.

.; Tовіn, K. At the elbow of another: learning to teach by coteaching. New York: Peter Lang Publishing, 2002.

Co-generative dialoguing and metaloguing: reflexivity of processes and genres. Forum Qualitative Social Research, Berlin: Freie Universität Berlin, v. 5, n. 3, artigo 7, 2004. Disponível em: <http://www.qualitative-research.net/index.php/fqs/ article/viewArticle/560>. Acesso em: 27 dez. 2015.

Rudge, D. W.; Howe, E. M. An explicit and reflective approach to the use of history to promote understanding of the nature of science. Science $\&$ Education, Dordrecht: Springer, v. 18, n. 5, p. 561-580, May 2009. Disponível em: <http://www.springerlink. com/content/q00t6u803px61611/>. Acesso em: 27 dez. 2015.

Scott, P.H.; Mortimer, E. F.; Aguiar, O. G. The tension between authoritative and dialogic discourse: a fundamental characteristic of meaning making interactions in high school science lessons. Sicence Education, New Jersey: Wiley, v. 90, n. 4, p. 605-631, July 2006. Disponível em: <http://onlinelibrary.wiley.com/doi/10.1002/sce.20131/abstract >. Acesso em: 27 dez. 2015.

SoAREs, E. S. Reprodução e produção das condições sociais em aulas de matemática: uma perspectiva trilhada na sala de aula. 2009.188f. Tese (Doutorado em Educação/Educação Matemática) - Universidade Federal de Minas Gerais, Belo Horizonte, 2009.

.; Goulart, M. I. M. Aulas compartilhadas na formação de licenciandos em matemática. Revista Brasileira de Educação, Rio de Janeiro: ANPEd; Campinas: Autores Associados, v. 13, n. 38, p. 306-324, maio/ago. 2008. Disponível em: <http://www.scielo. br/pdf/rbedu/v13n38/09.pdf>. Acesso em: 27 dez. 2015. 
Steiner, R. A filosofia da liberdade: fundamentos para uma filosofia moderna. São Paulo: Antroposófica, 1915/2000.

Treagust, D. F.; Duit, R. Conceptual change: a discussion of theoretical, methodological and practical challenges for science education. Cultural Studies of Science Education, Dordrecht: Springer, v. 3, n. 2, p. 297-328, July 2008. Disponível em: <http://www. springerlink.com/content/w112j317vh611t61/>. Acesso em: 27 dez. 2015.

Vamvakoussi, X.; Vosniadou, S. Understanding the structure of the set of rational numbers: a conceptual change approach. Learning and Instruction, San Francisco: Elsevier Education, v. 14, n. 5, p. 353-467, Oct. 2004. Disponível em: <http://www. sciencedirect.com/science/article/pii/S095947520400043X>. Acesso em: 27 dez. 2015. .; Christou, K. P.; Mertens, L.; Dooren, W. V. What fills the gap between discrete and dense? Greek and Flemish students' understanding of density. Learning and Instruction, San Francisco: Elsevier Education, v. 21, n. 5, p. 676-685, Oct. 2011. Disponível em: <http://www.sciencedirect.com/science/article/pii/S0959475211000259>. Acesso em: 27 dez. 2015.

Weinstein, M.; Broda, M. Resuscitating the critical in the biological grotesque: blood, guts, biomachismo in science/education and human guinea pig discourse. Cultural Studies of Science Education, Dordrecht: Springer, v. 4, n. 4, p. 761-780, Dec. 2009. Disponível em: <http://www.springerlink.com/content/r015206w628u7307/>.Acesso em: 27 dez. 2015.

\section{SOBRE OS AUTORES}

Eduardo Sarquis Soares é doutor em educação matemática pela Universidade Federal de Minas Gerais (UFMG). Professor da Universidade Federal de São João del-Rei (UFSJ).

E-mail: esarquis@gmail.com

Grace Marisa Miranda de Paula é mestre em educação pela Universidade Vale do Rio Verde (UNINCOR). Professora da Universidade Presidente Antônio Carlos (UNIPAC).

E-mail: gracemarisa40@gmail.com

Maria Lúcia Vieira é graduada em normal superior pela Universidade Federal de Ouro Preto (UFOP). Professora da Prefeitura Municipal de Ouro Branco.

E-mail: lucinhavieira398@hotmail.com

Recebido em maio de 2013 Aprovado em junho de 2015 